\title{
USING PERSONAL NORM MODEL TO EXPLAIN CYBER-HARASSMENT INTENTION AND BEHAVIOR
}

\author{
Godwin G. Udo, University of Texas at EI Paso, qudo@utep.edu \\ Kallol K. Bagchi, University of Texas at EI Paso, kbagchi@utep.edu
}

\begin{abstract}
This study uses the Norm Activation Model (NAM) to examine the factors that influence cyber-harassment intention and actual behavior. NAM is a well-grounded, attitude-based model that proves to be an effective predictor of the motivation and the role of emotions, which drive behavioral intentions. The proposed research model is described in this work-in-progress paper. Future research effort includes designing a survey instrument and collecting data to validate the model.
\end{abstract}

Keywords: cyber-Harassment, Personal Norms, Prosocial Intention, Social Influence, NAM

INTRODUCTION

As social media become an integral part of everyday means of communication, not only at personal level but also in governments, organizations, and businesses, cyber-harassment has gained in popularity as a topic of great concern among lawmakers, policy regulators, and law enforcement agencies. Cyber-harassment has many forms and can be described as behaviors carried out using digital media by individuals whose intention is to cause harm or discomfort on others (Zych, et al., (2019); Slonje, et al., (2013). The adverse effects of cyber-harassment are many and devastating including loss of goodwill, propagation of false information, emotional problems and even death in some extreme cases. Several technologies and techniques are now in use to check the ever-increasing growth rate of cyber-harassment (Blaya, 2019; Tokunaga, 2010). A few studies attempt to explain the phenomenon or to elucidate the reasons for its growth and how to curtail it. Majority of these studies focus on young people in grade schools (Tokunaga, 2010; Zych, et al., 2019; Topcu and Erdur-Baker, 2012; Festl, 2016). Some studies have explored the effect of empathy on the tendency to cyber-bullying (Schultze-Krumbholz, et al., 2016; Brewer and Kerslake, 2015; Barlińska, et al., 2015.

Very little study is done to explain the personal norms of the individuals who find it tempting or enticing to be practicing the anti-prosocial act of cyber-harassment. According to Udo, et al., (2015), individual personal norm may play a part in people's intention to be involved in harmful practices using information technology (IT). Though so many people agree concerning the effects of cyber-harassment on young people, in particular, and general public at large, very little is still known about its motivating factors (Tynes, et al, 2013). One area of cyber-harassment that is most lacking in terms of research effort is the social and psychological aspect (Zych, et al., (2019). There is a need for research approach that employs psychological models to examine cyber-harassment behaviors. One such model, which has been used in other types of behavior, is Norm Activation Model (NAM).

The NAM model theorized that the personal norms are influenced by two major factors: Awareness of Consequences (AC) and Ascription of Responsibility (AR). AC is being aware that performing (or not performing) a certain behavior can lead to certain outcomes or consequences. AR is the feeling of responsibility for performing a certain behavior.

The present study uses NAM to explain bullying intention and behavior with the aim of extending the understanding of the underlining factors motivate bullies. Using NAM theory to explain cyberbullying is a contribution that could be used to improve cyberbullying prevention programs. The knowledge of the relationship between personal norm and cyberbullying intention and behavior is a new effort in the containment of cyber-harassment and can help in policy formation and law enforcement to curtail the problems. 


\section{NAM AND CYBER-HARASSMENT}

The concept of Norm Activation Model (NAM) was proposed by Schwartz (1977) and used to demonstrate that people do good act such as donating to charity or working to keep the environment clean because they are driven by personal norm that would not allow them to do otherwise. According to the NAM model, behaviors emanate from personal norms (PN), which govern a sense of moral obligation to engage in or abstain from certain behaviors. Since this study, several authors have employed the model with various behaviors such as pro-environmental actions, individual energy consumption, blood donation, volunteering, etc. (Aronson et al, 2005; Batson and Powell, 2003; De Groot and Steg, 2010).

Cyber-Harassment is the use of a computer to cause a person harm such as anxiety, distress or psychological harm, including abusive, threatening or hateful emails and messages and the posting of derogatory information online Vieno, et al., 2011). It can be perpetuated in the following form:

- Cyberbullying, which involves sending threatening messages to targeted individuals using email or social media. The perpetuator can also attempt to deny the victim's access to the Internet or spread rumors about the targeted individual.

- Cyberstalking, which involves intimidating or unwanted advances on the social media over time.

- Flaming, which is a hostile, hateful, and offensive exchanges among social media users during discussions of heated real-world affairs. The common purpose of flaming is provocation of the users.

- Fraping, which happens when a perpetuator posts unsuitable content (such as racial slurs) on the victim's social networking accounts using the victim's name. The common purpose of fraping is to ruin the victim's reputation.

- Outing or doxing, which is when the bully intentionally reveals sensitive, personal information about the targeted individual with the aim of embarrassing and harassing him/her. The personal information could include pictures, videos, audio, and text.

Figure 1 illustrates NAM as used in the present study. The basic NAM shows how the relationships among AC, AR, and behavioral intension is mediated by PN (Steg and De Groot, 2010). In other words, PN is activated when an individual acknowledges that acting prosocially (or anti socially) will lead to positive (or negative) consequences for other individual (i.e. Awareness of Consequences) and when that individual feels responsible for the negative consequences that could result from his/her failure to act (i.e. Ascription of Responsibility). In this research, we demonstrate how this model can examine and explain cyber-harassment intentions.

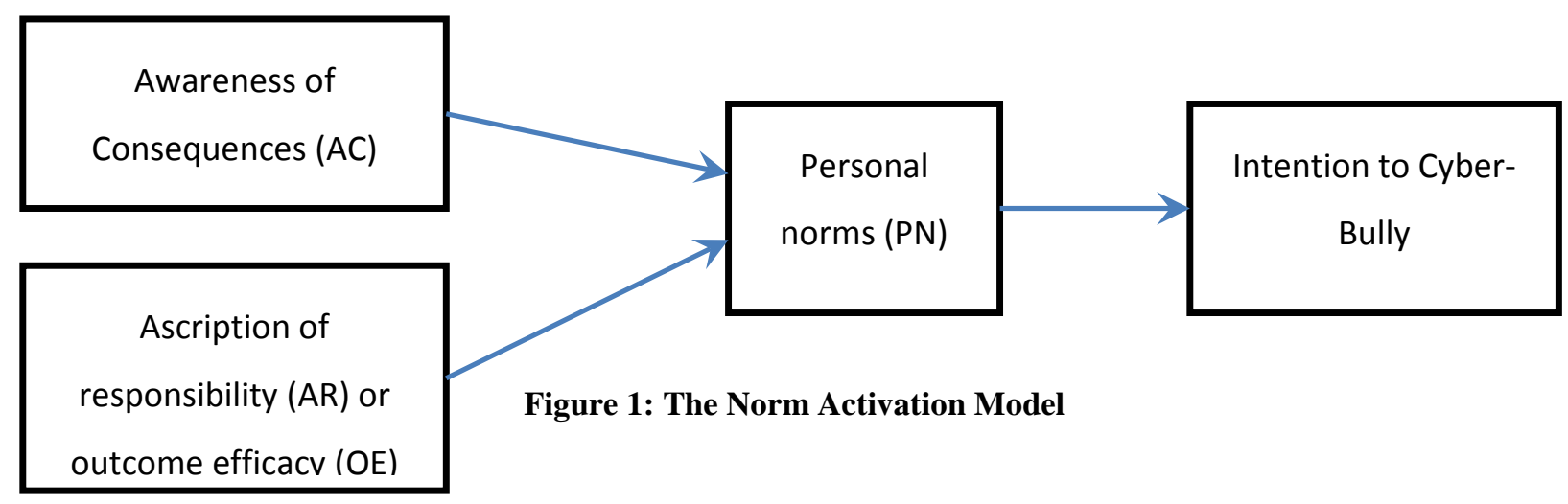

In past studies, NAM has been shown to capture or explain major societal events such as environmental concerns or blood donation all of which are positive actions. In the present study, we believe that the model can equally explain a negative or aggressive action such as cyber-harassment. Onwezen et al., (2013) seem to have the same view when they used NAM to examine the effects of pride (which results from positive actions) and guilt (which results from negative actions) on intentions. Their results indicated that both desirable and negative emotions have significant impacts on personal and social norms, which in turn positively or negatively affect behavior respectively. In the 
present study, we attempt to simulate cyber-harassment as a negative behavior or counter-prosocial behavior, which makes it suitable for the NAM.

\section{THE RESEARCH MODEL AND HYPOTHESES}

The models used in the study of IT-based undesirable behavior across social science disciplines are mostly cognitive and consequentialist in nature (Zych et al., (2019). For that reason, these models have limited explanatory power when applied to such psychological issues as cyber-harassment. Attitude-based models seem to perform better in such cases because they account more fully for the motivation and the role of emotions which drive behavioral intentions (Zych, et al., (2019). Trafimow and Finlay (1996) surveyed the literature and discover that out of 30 studies, twenty-nine demonstrated that attitude is a good predictor of intention. Peace et al., (2003) specifically conclude that attitude is the best predictor of intention to pirate software. Since NAM is an attitude-based, we suspect that it has a potential to better explain the factors that cause certain individuals to practice cyber harassment.

Awareness of Consequences (AC): is one of the two main factors in NAM and reflects the ability of an individual to be aware that performing (or not performing) a certain behavior can lead to certain outcomes or consequences. Several studies indicate that AC positively affects personal norm (PN) (De Groot and Steg, 2009; Bamberg and Moser, 2007; Peters, et al, 2011; Huijts, el al., 2013). De Groot and Steg (2009) used three separate studies (energy policy, car use reduction, and construction of distribution centers) to show that AC has a positive effect on PN. Also, Huijts, el al. (2013) find AC to be significant variable that explains PN in a study that used NAM to examine the intention of people to demonstrate against building hydrogen plants which have negative effect on the environment. Specifically, we predict that the more people are aware of the consequences of cyber-harassment, the more their personal norm will be influenced. The AC-related hypothesis for the study, as shown on the proposed model, is:

$\mathrm{H}_{1}$ : Awareness of Consequences of cyber-harassment has positive impact on the Personal Norms of cyberharassers.

Ascription of Responsibility (AR): is defined as the feeling of responsibility for performing a certain behavior. Schltz, et al., (2005) document the effect of AR on PN in their study of environment. The participants were asked to indicate how serious were each of the six environmental problems and their findings indicate that AR has a positive effect on PN. Steg and De Groot (2010) study leads to the same conclusion that AR influences PN in a positive way. With regard to the present study, we predict that if people have strong feeling of responsibility toward cyberharassment practice, their personal norm may be positively influenced but if they have no feeling of responsibility their PN will be unchanged toward cyber-harassment. Therefore, our AR-related hypothesis is as follows:

H2: Ascription of Responsibility for cyber-harassment has positive impact on the Personal Norms of cyberharassers.

Social Influence (SI): We have modified the NAM by introducing SI into the model. Venkatesh, et al., (2003) describe SI as the degree to which a person perceives it is not socially acceptable to use a certain technology. SI could be the individual's perception of his/her employer's, colleague's, or customer's opinion of his/her technology adoption and use (Venkatesh and Morris, 2000). It is the degree of attention an individual give to his/her referral groups (Hsu and $\mathrm{Lu}, 2004)$. Some authors have investigated the effect of SI on IT adoption and have come to the same conclusion that it has a significant influence (Eckhardt et al., 2009). This influence could enhance the motivation to (or restrain from) using the technology in question. In the case of cyber-harassment, we argue that a strong social influence may lead to a more positive personal norm and a less anti-social intention to engage in practice cyber-harassment. Social influence shape people's attitudes and behaviors. In the present research, PN is an attitude (Maity, et al., (2019). Personal norms are shaped by SI, whether the behavior is normative or non-normative. We expect that a strong SI may lead to a more positive PN. Accordingly, the following SI-related hypotheses are presented:

H3: Social Influence has positive impact on the Personal Norms of cyber-harassers.

H4: Social Influence has negative impact (i.e. discourages) on their intentions to engage in cyber harassers 
Personal Norms (PN): is described by Schwartz (1977) as "feelings of moral obligation to perform or refrain from, specific actions.” PN is activated when an individual acknowledges that acting pro-socially will lead to positive consequences for other individual (i.e. Awareness of Consequences) and when that individual feels responsible for the negative consequences that could result from his/her failure to act (i.e. Ascription of Responsibility). In effect, if the individual's norms are not activated, his/her actions (or no actions) will be judged as appropriate and so no prosocial action will take place. PN is therefore the mediator in the relationship between AR or CA and prosocial intentions which leads to actual behaviors. In the present study, PN is interpreted as the moral obligation people may feel that makes them engage or refrain from cyber-harassment. Those with little moral feelings will be more engaged in cyber-harassment than those with strong feelings. Some authors have established a significant positive relationship between PN and prosocial intensions (Schwartz, 1977; Huijts, el al., 2013). These authors have shown that PN guides behavioral intension. In fact, Huijts, el al. (2013) maintain that PN is the most important predictor of intension to act pro-socially. It is worth noting that personal norms are different from social norms. Social norms are activated and sustained by the external environment whereas personal norms stem from the inner person of the individual. The PN-related hypothesis can be stated as:

H5: The Personal Norm of cyber-harassers has negative impact (i.e. discourages) on their intensions to engage in cyber-harassment.

The first five hypotheses are for direct effect of NAM constructs and social influence on intention to cyber harass. There could be indirect or mediation effects of these constructs on each other. The six hypothesis that we plan to test is:

H6: There is no indirect effect of AR, AC and PN on each other.

\section{Instrument}

\section{METHODOLOGY}

Our proposed research model is based on literature review of previous studies and grounded on the theory of NAM. We developed a survey instrument based on current relevant literature in addition to modifying existing survey items from previous studies. The items that capture the three factors of NAM were taken from Steg et al., (2005) and the items for cyber-harassment were taken from Garaigordobil, (2017). A seven-point Likert scale was used to capture the constructs of variables in the study: strongly disagree to strongly agree Likert scales. We conducted a confirmatory factor analysis (CFA) in order to measure the model reliability while convergent validity was assessed by reviewing the $t$-tests for the factor loadings. All items used in the final analysis will have to load at acceptable levels (Chronbach $\alpha>0.70$; Nitse, et al., 2004).

\section{DISCUSSION AND CONCLUSION}

The present study aimed at using the NAM to explain the driving forces of cyber-harassment. We were motivated by the fact is NAM has been shown to explain altruistic behavior such as cyber-harassment. The implication of this finding will be of interest to social media vendors and the government agencies. The findings may be useful in that it will assist in finding ways to manipulate the AC, AR, and SI for potential cyber-harassers with the aim of increasing their personal norms then it is possible discourage or decrease their intention to engage in the practice. Programs that encourage social consciousness of the danger of cyber-harassment should be instituted and incentives should be provided for people to participate in such programs.

The present paper contributes to the understanding of the driving forces of cyber-harassment within the NAM model. The application of NAM theory to cyber-harassment provides assistance in the search for a new empirical understanding. This model seems to cover a wider range of factors affecting cyber-harassment. The research model can be used to formulate policies to reduce cyber-harassment practices. We hope we have proposed a research model that researchers can in the future to investigate cyber-harassment and/or related behaviors.

As a contribution to theory and research methodology, the present study has proposed a well-grounded model and the accompanying measurement constructs. It has increased our understanding of what measure could be effective in curbing cyber-harassment. The role of social influence on the cyber-harassers' intention to continue to practice cyber-harassment has been added the understanding of this phenomenon. The researchers and policy makers can 


\section{Issues in Information Systems}

Volume 21, Issue 4, pp. 36-41, 2020

know target or manipulate SI in order to minimize cyber-harassment. By establishing a program that internalizes the undesirability of cyber-harassment among peers and other social value systems, cyber-harassment could be mitigated in a more acceptable and subtle way. Another approach could be to isolate potential harassers from known ones who are likely to adversely influence the would-be harassers.

The future efforts will focus on collecting data and validating the proposed model.

\section{REFERENCES}

Aronson, E., Wilson, T. D., \& Akert, R. M. (2005). Social Psychology (5th edition). Upper Saddle River, NJ: Prentice-Hall.

Bamberg, S. and Moser, G. (2007). 20 years after Hines, Hungerford and Tomera: A new meta-analysis of psychosocial determinants of pro-environmental behavior. Journal of Environmental Psychology, 27, 14-25.

Barlińska, J., Szuster, A., \& Winiewski, M. (2015). The role of short- and long-term cognitive empathy activation in preventing cyberbystander reinforcing cyberbullying behavior. Cyberpsychology, Behavior and Social Networking, 18, 241-244.

Batson, C., \& Powell, A. A. (2003). Altruism and prosocial behavior. In T. Millon \& M. J. Lerner (Eds.), Handbook of psychology: Personality and social psychology, vol. 5 (pp. 463-484). Hoboken, NJ: John Wiley \& Sons Inc.

Brewer, G., \& Kerslake, J. (2015). Cyberbullying, self-esteem, empathy and loneliness. Computers in Human Behavior, 48, 255-260.

Blaya, C. (2019). Cyberhate: A review and content analysis of intervention strategies. Aggression and Violent Behavior, 45, 163-172.

De Groot, J. I. M. and Steg, L. (2010), Morality and nuclear energy: Perceptions of risks and benefits, personal norms, and willingness to take action related to nuclear energy, Risk Analysis, 30(9), 1363 - 1373.

Eckhardt, A., Laumer, S., and Weitzel, T. (2009). Who influences whom? Analyzing workplace referents' social influence on IT adoption and non-adoption. Journal of Information Technology, 24, 11-24.

Festl, R. (2016). Perpetrators on the internet: Analyzing individual and structural explanation factors of cyberbullying in school context. Computers in Human Behavior, 59, 237-248.

Garaigordobil, M. (2017). Psychometric properties of the Cyberbullying Test, a screening instrument to measure cybervictimization, cyberaggression and cyberobservation. Journal of Interpersonal Violence, 23, 3556-3576.

Hsu, C-L., and Lu, H-P. (2004). Why do people play on-line games? An extended TAM with social influences and flow experience. Information \& Management, 41(7), 853 - 868.

Huijts, N.M.A., De Groot, J.I.M., Molin, E.J.E. and van Wee, B. (2013). Intention to act towards a local hydrogen refueling facility: Moral considerations versus self-interest. Transport Research, 63-74.

Maity, M., Bagchi, K., Shah, A. \& Misra, A. (2019). Explaining Normative Behavior in Information Technology Use. Information Technology \& People, 32(1), 94-117.

Onwezen, M.C., Antonides, G. and Bartels, J. (2013). The Norm Activation Model: An exploration of the functions of anticipated pride and guilt in pro-environmental behavior. Journal of Economic Psychology, 39, 141 - 153.

Peace, A.G., Galletta, D.F., and Thong, J.Y.L. (2003). Software piracy in the workplace: A model and empirical test, Journal of Management Information Systems, 20(1), 153 - 177. 
Peters, A., Cutscher, H., and Scholz, R.W. (2011). Psychological determinants of fuel consumption of purchased new cars. Transportation Research Part F: Traffic. Psychology and Behaviour, 14, 229-239.

Schwartz, S. H. (1977). Normative Influences on altruism. In L. Berkowitz (Ed.), Advances in experimental social psychology (Vol. 10, pp. 221-279). New York: Academic Press.

Schultze-Krumbholz, A., Schultze, M., Zagorscak, P., Wölfer, R., \& Scheithauer, H. (2016). Feeling cybervictims' pain-The effect of empathy training on cyberbullying. Aggressive Behavior, 42, 147-156.

Slonje, R., Smith, P. K., \& Frisén, A. (2013). The nature of cyberbullying, and strategies for prevention. Computers

in Human Behavior, 29, 26-32.

Steg, L. and de Groot, J. (2010). Explaining prosocial intentions: Testing causal relationships in the norm activation model. British Journal of Social Psychology, 49, 725 - 743.

Steg, L., Dreijerink, L., \& Abrahamse, W. (2005). Factors influencing the acceptability of energy policies: Testing VBN theory: Journal of Environmental Psychology, 25, 415-425.

Tokunaga, R. S. (2010). Following you home from school: A critical review and synthesis of research on cyberbullying victimization. Computers in Human Behavior, 26(3), 277-287.

Topcu, Ç., \& Erdur-Baker, O. (2012). Affective and cognitive empathy as mediators of gender differences in cyber and traditional bullying. School Psychology International, 33, 550-561.

Trafimow, D. and Finlay, K.A. (1996). The importance of subjective norms for a minority of people: Betweensubjects and within-subjects. Personality and Social Psychology Bulletin, 22, 820-828.

Tynes, B.M., Rose, C.A., \& Markoe, S.L. (2013). Extending campus life to the Internet: Social media, discrimination, and perceptions of racial climate. Journal of Diversity in Higher Education, 6(2), 102-114,

Udo, G., Bagchi, K., \& Maity, M. (2016). Exploring factors affecting digital piracy using the Norm Activation and UTAUT models: The role of national culture. Journal of Business Ethics, 135(3), 517-541.

Venkatesh, V., and Morris, M. G. (2000). Why don’t men ever stop to ask for directions? Gender, social influence, and their role in technology acceptance and usage behavior. MIS Quarterly, 24(1), 115-139.

Venkatesh, V., Morris, M., Davis, G., Davis, F. (2003). User Acceptance of Information Technology: Toward a Unified View, MIS Quarterly, 7(3), 425-478.

Zych, I., Baldry, A.C., Farrington, D.P., \& Llorent, V. J. (2019). Are children involved in cyberbullying low on empathy? A systematic review and meta-analysis of research on empathy versus different cyberbullying roles. Aggression and Violent Behavior, 45, 83-97. 